\title{
Reconstructing Salmon Abundance in Rivers: An Initial Dendrochronological Evaluation
}

James M. Helfield

Western Washington University, james.helfield@wwu.edu

Robert J. Naiman

University of Washington

Deanne C. Drake

University of Washington

Follow this and additional works at: https://cedar.wwu.edu/esci_facpubs

Part of the Environmental Sciences Commons

\section{Recommended Citation}

Helfield, James M.; Naiman, Robert J.; and Drake, Deanne C., "Reconstructing Salmon Abundance in Rivers: An Initial Dendrochronological Evaluation" (2002). Environmental Sciences Faculty and Staff Publications. 18.

https://cedar.wwu.edu/esci_facpubs/18 


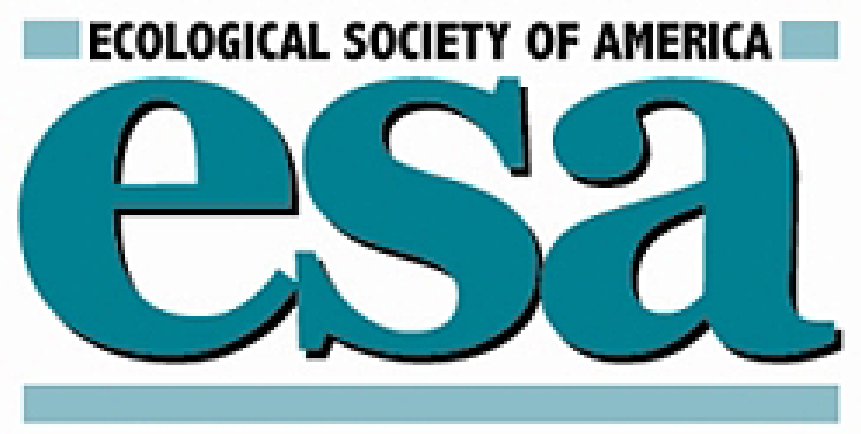

Reconstructing Salmon Abundance in Rivers: An Initial Dendrochronological Evaluation Author(s): Deanne C. Drake, Robert J. Naiman and James M. Helfield

Source: Ecology, Vol. 83, No. 11 (Nov., 2002), pp. 2971-2977

Published by: Ecological Society of America

Stable URL: http://www.jstor.org/stable/3071832

Accessed: 20/11/2014 16:57

Your use of the JSTOR archive indicates your acceptance of the Terms \& Conditions of Use, available at http://www.jstor.org/page/info/about/policies/terms.jsp

JSTOR is a not-for-profit service that helps scholars, researchers, and students discover, use, and build upon a wide range of content in a trusted digital archive. We use information technology and tools to increase productivity and facilitate new forms of scholarship. For more information about JSTOR, please contact support@ jstor.org. 


\title{
RECONSTRUCTING SALMON ABUNDANCE IN RIVERS: AN INITIAL DENDROCHRONOLOGICAL EVALUATION
}

\author{
Deanne C. Drake, ${ }^{1}$ Robert J. Naiman, ${ }^{1}$ and James M. Helfield ${ }^{2}$ \\ ${ }^{1}$ School of Aquatic and Fishery Sciences, University of Washington, Box 355020, Seattle, Washington 98195 USA \\ ${ }^{2}$ College of Forest Resources, University of Washington, Box 352100, Seattle, Washington 98195 USA
}

\begin{abstract}
Decision-makers concerned with salmon or their stream habitats are faced with many persistent, difficult questions including: how large and variable were these populations before European settlement? Here, we examine the feasibility of reconstructing salmon abundance using links between marine nutrients carried upstream by Pacific salmon (Oncorhynchus spp.) and growth of dominant riparian trees in two Alaskan systems. We employ standard dendrochronology methods and regression models to quantify relationships between annual tree-ring growth, salmon escapement, and the climate pattern that affects oceanic production of Northeast Pacific salmon stocks, the Pacific Decadal Oscillation (PDO). We find that known, annual salmon escapement is significantly related to tree-ring growth at two sites in the Pacific coastal rainforest (PCRF) $\left(r^{2}=0.23, P<0.05\right.$ at each site), but not at two sites in the boreal forest. We then use relationships established at PCRF sites to reconstruct preliminary salmon spawning abundances to 1820 A.D. The PDO was not correlated with local 19-yr salmon escapement records and could not be used in reconstructions. Reconstructions compare favorably to southeastern Alaska fisheries catch data from 1924 to 1994 (Pearson correlation $=0.301[P=0.02]$ and $0.401[P<0.01]$ ). This study demonstrates the promise and utility of dendrochronology for reconstructing salmon returns to streams.
\end{abstract}

Key words: dendrochronology; fertilization; marine-derived nutrients; nutrient cycling; Onchorynchus spp.; Pacific Decadal Oscillation, PDO; Picea glauca; Picea sitchensis; riparian forest; salmon; Sitka spruce; white spruce.

\section{INTRODUCTION}

In the 20th century, populations of anadromous Pacific salmon (Oncorhynchus spp.) have declined significantly throughout much of their spawning range in North America. As human pressures on salmon habitats intensify, paleoecological reconstructions of prehistorical salmon abundance will be key in determining realistic management and conservation goals. Using records of nitrogen isotopes in lake sediments, Finney et al. (2000) reconstructed a 300-yr history of sockeye salmon (O. nerka) abundance in the Bristol Bay and Kodiak regions of Alaska. This study provided a first look at prehistorical salmon populations and new insights into the complex relationship between marine productivity and inland lake ecology, but these techniques are generally not applicable to river environments, which rarely contain reliable, continuous sediment records. Historical records of salmon escapement (i.e., salmon that escape fisheries to spawn) rarely exceed $60 \mathrm{yr}$ and cannot satisfactorily describe natural variability of river populations, especially in the context of anthropogenic depletion of stocks. Here, we examine tree-ring growth as a potential proxy of annual salmon abundance in streams. We first examine relationships between annual growth of riparian trees, ma-

Manuscript received 4 March 2002; revised 30 April 2002; accepted 8 May 2002. rine-derived nutrients (MDN) transported upstream by salmon (escapement), and climate variables. We operate under the hypothesis that annual variation in escapement is reflected in tree-ring chronologies, especially where tree growth is nutrient-limited. We then contrast escapement-tree growth-climate relationships in relatively warm, wet, productive Alaskan Pacific coastal rainforest (PCRF) to drier, cooler, less productive boreal forest sites. Finally, we use resulting empirical relationships to reconstruct escapement to 1820 A.D. and compare the reconstruction to regional fisheries data.

Annual growth of trees along the Pacific Coast of North America is determined, in large part, by climate (precipitation and temperature) and nutrient availability (Oliver and Larson 1996). The climate pattern linked to oceanic productivity (and consequent strength of Pacific salmon stocks) is referred to as the Pacific Decadal Oscillation (PDO; Francis and Hare 1994, Mantua et al. 1997, Hare et al. 1999). The PDO operates primarily over the North Pacific and shifts in polarity every 20-30 yr. In the last century, shifts occurred in 1925, 1947, and 1977 (PDO is currently positive in polarity). Positive polarity $\mathrm{PDO}$ is associated with warmer, wetter conditions and higher stream discharge in Alaska and warmer but dryer conditions in southern salmon ranges. During the positive phase of PDO northern salmon stocks experience favorable condi- 
tions (reflected in relatively high abundance), while southern stocks appear to suffer. This relationship is reversed during the negative phase. $\mathrm{PDO}$, an integrated climatic index, is sometimes reflected in tree-ring chronologies (e.g., Biondi et al. 2001).

In the last $10 \mathrm{yr}$ there have been dramatic discoveries regarding the importance of salmon-borne MDN to stream ecosystems (Willson et al. 1998, Cederholm et al. 1999, Naiman et al. 2002). Biomass gained in the ocean by salmon and transported upstream contributes nutrients and organic matter to freshwater ecosystems (Kline et al. 1990, Bilby et al. 1996, Wipfli et al. 1998), riparian vegetation (Ben-David et al. 1998, Hildebrand et al. 1999, Helfield and Naiman 2001), and wildlife (Hildebrand et al. 1996, Ben-David et al. 1997, Willson et al. 1998) and is key in growth and survival of the next generation of salmon (Bilby et al. 1998, Naiman et al. 2002). Alaskan Sitka spruce (Picea sitchensis) and white spruce ( $P$. glauca) grow 3.0 and 1.5 times faster, respectively, on rivers where salmon spawn relative to nearby reference sites (Helfield 2001, Helfield and Naiman 2001). It is also known that annual salmonborne nutrients affect riparian community structure (Bartz 2002). Despite these advances, understanding of complex biogeochemical cycles that mediate transfer of MDN between soils, animals, and plants of riparian systems remains limited, as does the understanding of how salmon-borne nutrient inputs vary through time.

\section{Methods AND Data \\ Study sites and design}

We collected increment cores at eight riparian forest sites. Four of the sites were located on salmon-bearing streams, and each was paired with a nearby, non-salmon-bearing stream (i.e., reference site). All cores were collected within $150 \mathrm{~m}$ of the active channel. We established two site pairs in the southeast Alaskan PCRF and two pairs in the southwest Alaskan boreal forest. Salmon play important roles in both of these climatically and ecologically contrasting systems. Mechanisms of salmon-borne MDN delivery to the riparian forest in both the boreal forest and PCRF include hyporheic flow, piscivore activity, and flooding, but the relative importance of these factors at each site has not been quantified. PCRF sites were located on the Indian and Kadashan rivers, both tributaries of Tenakee Inlet $\left(\sim 57^{\circ} \mathrm{N}, 135^{\circ} \mathrm{W}\right)$. Reference sites were found upstream of salmon sites, beyond barriers to migrating salmon, and were environmentally similar to the salmon sites (Helfield and Naiman 2001). PCRF sites are wet, receiving a mean of $236 \mathrm{~cm}$ of precipitation annually. These mature coastal forests are dominated by Sitka spruce and western hemlock (Tsuga heterophylla) and support a dense vegetative understory. Nitrogen is generally thought to be the limiting nutrient in PCRF coniferous forests (Harris and Farr 1974, Chabot and
Mooney 1985), although specific soil chemistry of the sites is unknown.

Boreal forest sites are located in the Wood Lakes River system of southwest Alaska $\left(\sim 59^{\circ} \mathrm{N}, 159^{\circ} \mathrm{W}\right)$. These sites are subject to both maritime and continental influences, receiving an average of $50 \mathrm{~cm}$ of precipitation annually, and are dominated by white spruce and paper birch (Betula papyrifera) interspersed with areas of moist tundra grassland and low-growing shrubs. Boreal forest white spruce respond, in terms of nutrients, primarily to soil nitrogen supply (Van Cleve and Yarie 1986) although the presence of $\mathrm{N}$-fixing alder may shift nutrient limitation to phosphorus.

We collected 91 5-mm diameter increment cores (87 dating to 1900 A.D. or earlier) from the eight sites (Table 1). Manual increment borers were used to collect cores from Sitka spruce at the PCRF sites and from white spruce at the boreal forest sites. Sample size varied from 7 to 15 trees per site.

\section{Data}

PCRF annual spawning escapements (exact weir counts on the Kadashan River) are available for 19691987 and vary from 39000 to 295000 salmon annually over that period. We extrapolated Kadashan River escapement directly to the Indian River; the two rivers are geographically proximate $(6 \mathrm{~km})$, and both are dominated by pink (Onchorynchus gorbuscha) and chum (O. keta) salmon, which account for $>99 \%$ of spawning salmon in each river (Alaska Department of Fish and Game Region 1, unpublished data). Boreal forest annual escapement estimates are unexpanded, in-stream counts conducted on $1 \mathrm{~d}$ at the height of each spawning season from 1956 to 1999 . Boreal forest escapements are probably accurate at a coarse scale (low escapement years are reflected by low counts in those years), but clearly are not as accurate as direct counts and must be interpreted with some caution. Sockeye salmon spawn in Hanson and Happy creeks (spawning sites); escapement varied, respectively, from 172 to 13000 and from 155 to 25000 fish annually (Rogers and Rogers 1998). We used 1925-1999 PDO indices from Hare et al. (1999; updated values available online) ${ }^{3}$ for regression analyses. PDO indices to 1900 are available, but those predating 1925 are considered to be less reliable (Robert Francis, personal communication) and were excluded from the analyses.

\section{Analyses}

We prepared increment cores using standard procedures (Phipps 1985) and measured ring widths to 0.001 $\mathrm{mm}$. We cross-dated cores using skeleton plots and the dendrochronology program COFECHA (Holmes 1983). Ring-width series were standardized into relative, dimensionless growth indices for each site using

${ }^{3}$ URL: 〈ftp://ftp.atmos.washington.edu/mantua/pnw_impacts/ INDICES/PDO.latest $\rangle$ 
TABLE 1. Tree-ring chronologies by ecoregion and site, statistics describing growth indices vs. escapement and climate variables, and autoregression estimates.

\begin{tabular}{|c|c|c|c|c|c|c|}
\hline \multirow[b]{3}{*}{ Site } & \multirow[b]{3}{*}{$\begin{array}{l}\text { No. } \\
\text { cores }\end{array}$} & \multirow{2}{*}{\multicolumn{2}{|c|}{$r^{2}$}} & \multirow{3}{*}{$\begin{array}{c}\text { AR1 } \\
\text { (escapement } \\
\text { relationship } \\
\text { removed from } \\
\text { chronology) } \ddagger\end{array}$} & \multicolumn{2}{|c|}{$r^{2}$} \\
\hline & & & & & \multirow{2}{*}{$\begin{array}{l}\text { Precipitation } \\
\text { growing } \\
\text { season sum }\end{array}$} & \multirow{2}{*}{$\begin{array}{c}\text { Annual } \\
\text { heat sum } \\
\text { (base } 4^{\circ} \mathrm{C} \text { ) } \S\end{array}$} \\
\hline & & $\begin{array}{c}\text { Escape- } \\
\text { ment } \dagger\end{array}$ & $\begin{array}{c}\text { PDO } \\
1925-1999\end{array}$ & & & \\
\hline \multicolumn{7}{|l|}{ Pacific coastal rainforest (Sitka spruce) } \\
\hline Kadashan River, no salmon & 7 & $0.10 \|$ & 0.009 & 0.66 & 0.00 & 0.01 \\
\hline Kadashan River, salmon & 11 & 0.23 & $0.17 \#$ & 0.28 & 0.04 & 0.11 \\
\hline Indian River, no salmon & 13 & $0.01+\dagger$ & $0.30 \ddagger \ddagger$ & 0.82 & 0.00 & 0.11 \\
\hline Indian River, salmon & 13 & 0.23 & 0.20 & 0.04 & 0.05 & 0.13 \\
\hline \multicolumn{7}{|l|}{ Boreal forest (white spruce) } \\
\hline Little Whitefish Creek, no salmon & 13 & & 0.03 & 0.83 & 0.01 & 0.05 \\
\hline Hansen Creek, salmon & 9 & 0.08 & 0.00 & 0.20 & 0.02 & 0.04 \\
\hline Lake Aleknagik Shore, no salmon & 15 & & 0.01 & 0.06 & 0.00 & 0.07 \\
\hline Happy Creek, salmon & 10 & 0.02 & 0.02 & 0.25 & 0.08 & 0.01 \\
\hline
\end{tabular}

$\dagger$ Nineteen years of escapement data are available for Pacific Coastal Rainforest (PCRF) sites; 41 yr are available for boreal forest sites.

$\ddagger$ AR 1 values are lag-1 autoregression coefficients calculated after escapement was accounted for. High values at reference sites support the assertion that escapement is not correlated with annual growth at reference sites.

$\S$ Forty-six years of precipitation and temperature data are available for PCRF sites; $49 \mathrm{yr}$ are available for the boreal forest sites.

$$
\begin{aligned}
& \| P=0.03, \text { df }=18 . \\
& \mathbb{I} P=0.04, \mathrm{df}=74 \\
& \# P=0.01, \mathrm{df}=74 . \\
& \dagger \dagger P=0.04, \mathrm{df}=18 . \\
& \ddagger \ddagger P=0.01, \text { df }=74 .
\end{aligned}
$$

the program ARSTAN (Cook 1985); we used a 128-yr cubic smoothing spline with a $50 \%$ frequency cutoff for detrending tree-ring series to preserve high and medium frequency variability while removing low-frequency trends. Growth indices represent relative annual growth by site and are corrected for decreasing ringwidth as trees grow larger in diameter. Average site chronologies were all $>122 \mathrm{yr}$.

Linear regression models were used to examine escapement vs. growth indices and PDO at all sites. Quadratic models were tested, but linear models provided the best fit in all cases. We also compared the eight site chronologies to local, annual growing-season precipitation and annual heat sum based on a $4^{\circ} \mathrm{C}$ threshold (Western Regional Climate Center 2001). ${ }^{4}$ We calculated first-order autocorrelation coefficients (AR1 values) for all chronologies after escapement was accounted for. High AR1 values were expected at reference sites; no variation was removed with escapement, so most of the original AR process remained. The statistical program SPSS (Windows version 7.0; SPSS 1999) was used to produce all regression and autocorrelation statistics.

We used years of known escapement (1969-1987) as a calibration set to reconstruct prehistoric escapement to 1820 at the PCRF sites. The calibration set included growth index values of 0.83 to 1.29 at the Indian River and 0.84 to 1.32 at the Kadashan River. Growth index values outside of the calibration sets were excluded from the reconstructions (for example,

${ }^{4}$ URL: 〈http://www.wrcc.dri.edu/〉
Kadashan River growth indices from the 1949-1957 period were all $<0.83$ and were excluded). Those years excluded from the reconstructions were almost all years of very low growth (suggesting low escapements). Reconstructions were based on chronologies containing a minimum of three trees (as chronologies extend back in time, younger trees drop out of the chronology).

\section{RESULTS}

\section{Tree growth-escapement-climate relationships}

As escapement increases, so does annual growth of Sitka spruce at both PCRF salmon sites (Table 1); this relationship is not seen at the reference sites or any of the boreal forest sites. PDO is significantly correlated with growth at both PCRF salmon sites and one reference site, but bears no relation to the Kadashan River reference site chronology. Indian River growth indices are most strongly correlated with escapement lagged by 1 yr (i.e., a growth response 1 yr following MDN input; Table 1), with a weaker but significant unlagged relationship $\left(r^{2}=0.20, P=0.03\right)$. Growth indices at the Kadashan River sites are most strongly correlated with unlagged escapement. Escapement lagged by 2 and $3 \mathrm{yr}$ is not significantly correlated with growth at any of the sites.

Tree-ring growth index is not correlated with precipitation or annual heat sum at any of the sites (Table 1). At the PCRF sites, climate variables appear to be best represented by PDO, an integrated climatic signal correlated with annual tree growth at three of four sites. 


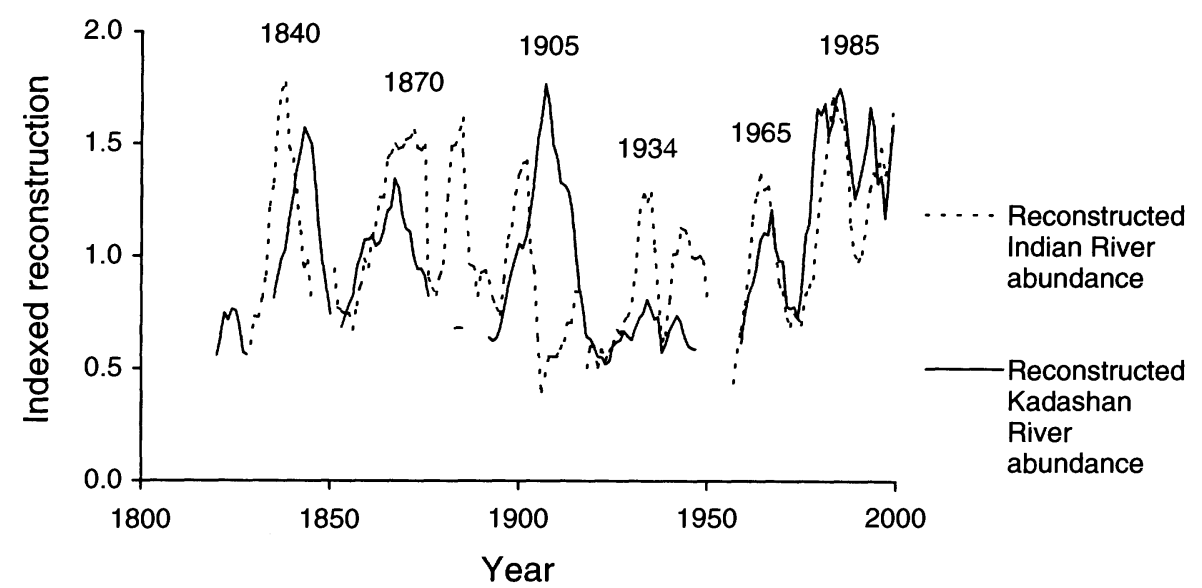

FIG. 1. Pacific coastal rainforest (PCRF) pink and chum salmon abundance reconstructions to 1820 (indexed 5-yr running means). Strong, mostly synchronous decadal-scale patterns with a $20-35$ yr period are seen in both systems. The calibration set included growth index values of 0.83-1.29 at the Indian River and 0.84-1.32 at the Kadashan River. Growth index values outside of the calibration sets were excluded from the resconstructions (for example, Kadashan River growth indices from 1949-1957 were all $<0.83$ and were not used).

Boreal forest white spruce chronologies, however, were not correlated with PDO (Table 1).

\section{Reconstructions}

While PDO is closely correlated with large-scale regional salmon catch patterns over the last $75 \mathrm{yr}$ (Pearson correlation $=0.71, P<0.01)$, the $19 \mathrm{yr}$ of known Kadashan River escapement are only weakly related to PDO $\left(r^{2}=0.12, P=0.07\right)$, and inclusion of PDO as a predictor did not improve the estimation of escapement. Escapement for year $i\left(E_{i}\right)$ was calculated using Kadashan River growth index (KGI) or Indian River growth index (IGI).

$E_{i}($ Kadashan River $)=-79925+\left(220943 \times \mathrm{KGI}_{i}\right)(1)$

$E_{i}($ Indian River $)=-103525+\left(250741 \times \mathrm{IGI}_{i}\right)$.

We calculated 5-yr running averages of the reconstructed values to remove high-frequency variation and to emphasize multi-year patterns (Fig. 1). The reconstructions reflect general patterns of southeastern Alaska regional pink and chum salmon catch (which is commonly used to approximate regional abundance; Fig. 2A) and PDO (Fig. 2B). Boreal forest chronologies could not be related to escapement, and, therefore, could not be used to produce reconstructions.

\section{Chronology characteristics}

Inter-series correlations (a measure of within-site tree-ring series similarity produced by ARSTAN) ranged from 0.23 to 0.38 , values typical for the Pacific Northwest. AR1 values (after escapement was accounted for) are relatively low at both PCRF salmon sites but high at reference sites, suggesting that escapement (MDN input) is a major driver of PCRF spawning site tree growth (Table 1). Escapement is not correlated with growth at the reference sites, which helps elimi- nate possible mistaken identity of a climate signal merely correlated with escapement. Boreal forest AR 1 values were variable, and it is clear that the primary driver of annual tree growth was not identified.

\section{Discussion}

Fertilization effects of salmon-borne MDN were evident in the PCRF tree-ring chronologies but not the boreal forest chronologies. By quantifying relationships between annual growth and escapement in the PCRF, we produced preliminary salmon abundance reconstructions that compare well to $75 \mathrm{yr}$ of southeastern Alaska pink and chum salmon catch (Fig. 2A). Since pink and chum comprise $>99 \%$ of the adult salmon spawning in the PCRF streams, our discussion is limited to those species. Reconstructed abundance and catch (indexed to mean $=1$ ) generally increase and decrease in concert, although the magnitude of changes differs considerably. Southeastern Alaska catch increases from 1973 to 1993; this is captured by the reconstruction until approximately 1980 , when reconstructed abundances stabilize at a relatively high level. This may demonstrate a threshold where nutrient limitation is overcome and additional MDN contribution has little effect on annual tree-ring growth. A substantial decline in reconstructed abundance (reflecting growth) at both sites from 1936 to 1943 is probably a result of a larger-scale climate event. Reference sites and an independent Sitka spruce chronology $\sim 300 \mathrm{~km}$ from the study sites (Wiles and Calkin 1995) all display decreased growth rates during this period. Local salmon abundance may or may not have responded to this event. The 1950 s are also characterized by very low annual growth rates (outside of the range of growthescapement equations); regional catch and PDO were also low during these years. All evidence implies low escapement during this period. 


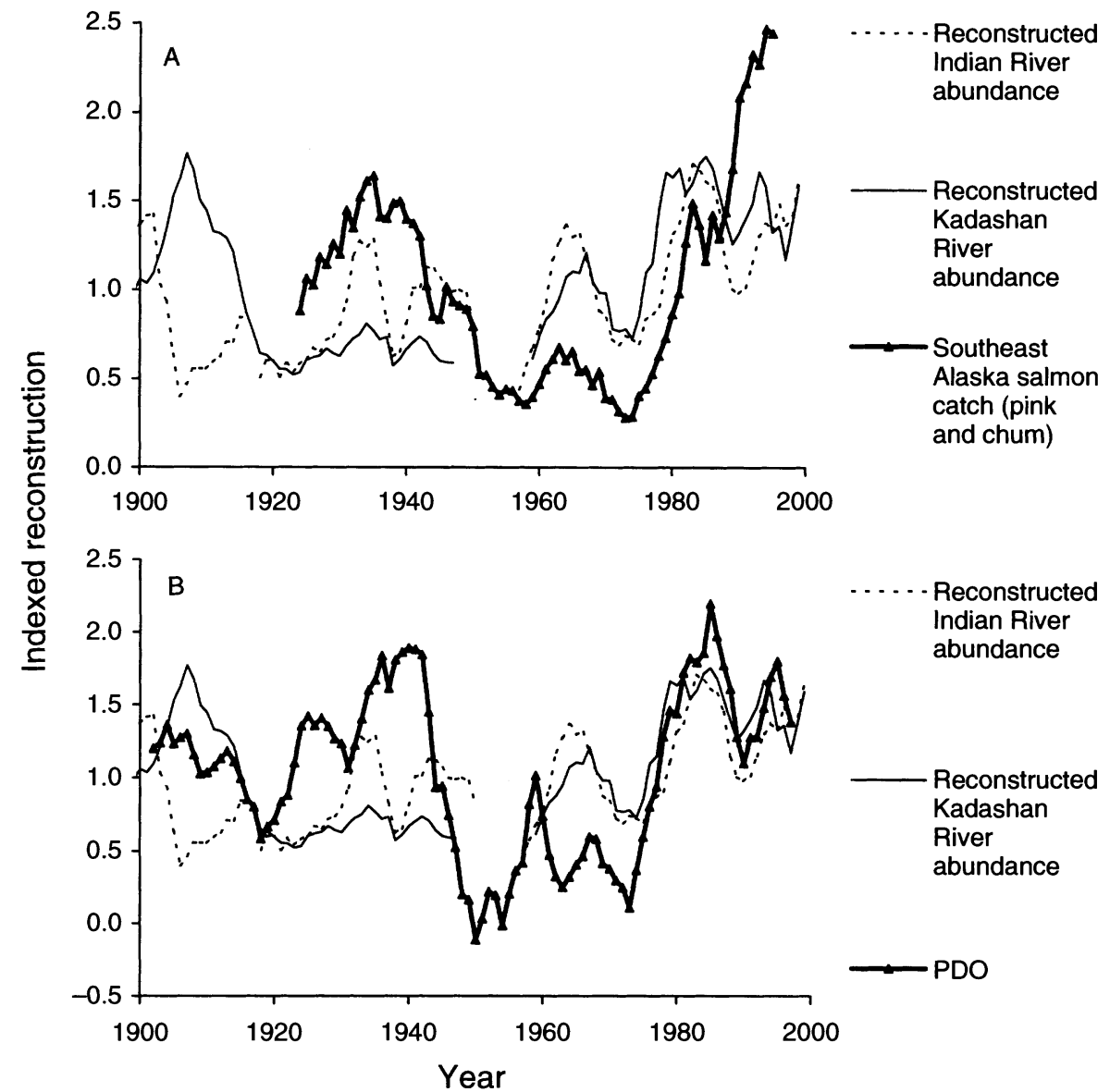

FIG. 2. Comparison of salmon abundance reconstructions to (A) regional catch data and (B) Pacific Decadal Oscillation (PDO; Hare et al. 1999). Reconstructions reflect general patterns of catch data and PDO to a lesser extent. Indian River reconstruction vs. regional catch, Pearson correlation $=0.301(P=0.02)$; Kadashan River reconstruction vs. regional catch, Pearson correlation $=0.401(P<0.01)$; Indian River reconstruction vs. PDO, Pearson correlation $=0.328(P=0.02)$; Kadashan River reconstruction vs. PDO, Pearson correlation $=0.363(P<0.01)$.

Finney et al. (2000) reconstructed $300 \mathrm{yr}$ of sockeye salmon abundance in five Alaskan lake systems using $\delta^{15} \mathrm{~N}$, diatoms, and cladoceran microfossils in lake sediments. They found evidence of large-scale sockeye abundance variation correlated with sea surface temperature and a long-term decline beginning in the 1920s associated with commercial catch. The pink and chum reconstructions presented here do not track reconstructed sockeye abundance. For example, pink and chum reconstructions are characterized by strong decadal-scale periodicity that is not evident in the sockeye series. This may be a result of differences in the temporal resolution of tree rings and lake sediments or population-level characteristics of the different species. The populations are also separated by a distance of $\sim 1000 \mathrm{~km}$ and are subjected to separate fisheries, so close synchrony in the reconstructions was not expected.

While clearly resembling long-term southeastern Alaska catch, these reconstructions are admittedly limited; they are based on a short (19-yr) time series, and many factors other than MDN input affect annual treering formation. Basing subsequent reconstructions on longer escapement records and dendrochemical methods (currently under development) should improve the quality of reconstructions. More sophisticated models that incorporate reference site chronologies (by subtracting the common signal from salmon site chronologies) may also improve reconstructions and allow more confidence in single-year estimates. An appealing aspect of dendroecology-based reconstruction is the time scale it potentially encompasses with annual resolution; living trees in the Pacific Northwest commonly live to $400 \mathrm{yr}$ in protected areas, and fallen trees preserved in streambeds date to $>1200 \mathrm{yr}$ BP (Hyatt and Naiman 2001). The reconstructions presented here, although limited, still allow an evaluation of long-term salmon abundance cycles and contrast of historical abundance to modern escapement.

Since PDO is correlated with regional salmon catch over long time periods (Fig. 2B), it is not surprising that the reconstructions reflect known PDO cycles to 
a degree (catch vs. PDO Pearson correlation $=0.71$, $P<0.01, N=72$ ). Reconstructed salmon abundance predating 1900 cycles at $20-35$ yr intervals. This is approximately half the period of PDO, which cycles every 40-60 yr (Hare et al. 1999). The 20-35 yr periodicity in reconstructions may be put into perspective by examining 1957-1965, during which a dramatic change from low to high abundance (reconstructed) corresponds to a much smaller fluctuation in regional catch (Fig. 2A). Escapement during this time may actually have been large in the Kadashan and Indian rivers relative to regional catch, depending on local environmental conditions and fisheries. Reconstructed abundance from 1900 to 1920 is relatively high in the Indian River, but relatively low in the Kadashan River. Shortterm, system-level differences in annual abundance such as this may be results of debris flows that temporarily cover spawning habitat, disease outbreaks, local fire, or other small-scale disturbances.

Annual variation of white spruce growth at the boreal forest sites appears to be dictated by factor(s) not ex amined here and could not be used to reconstruct escapement. We had no a priori expectation of the dif ferences observed between the boreal forest and PCRF. Annual ring formation of white spruce is related closely to growing-season temperature at its northern range limits (Garfinkel and Brubaker 1980). Annual growth at our study sites may depend on soil temperature, cloud cover, or another environmental variable not captured by the available temperature and precipitation records. Nevertheless, average yearly growth was times higher in trees near salmon streams compared to reference sites (Helfield 2001), suggesting a muted fertilization effect. A possible explanation for this is higher rates of nutrient cycling at PCRF sites may allow MDN input to influence growth annually, while othe limitations or long-term lags between MDN input and availability to plants (i.e., slow soil cycling rates) mas obscure an annual signal in boreal forest trees.

Climate patterns are entwined with growth and survival of salmon at sea and also strongly influence riparian forest dynamics. Unfortunately, experimental data linking annual responses of riparian forests to MDN inputs do not exist. The data presented here show that annual tree growth chronologies have the potential to provide a record of fertilization effects in PCRF riparian systems. Reconstruction methods may be more broadly applied when combined with dendrochemical measures such as the per mil deviation in ${ }^{15} \mathrm{~N}$ abundance from atmospheric $\mathrm{N}_{2}\left(\delta \%{ }^{15} \mathrm{~N}\right)$, in which the rel ative concentration of marine-derived nitrogen in individual tree rings could be used to reconstruct annual MDN contributions to a system. It is not currently pos $\rightarrow$ sible to determine nitrogen isotope ratios in wood with confidence; mobile $\mathrm{N}$ compounds (sap residues) are difficult to remove from wood and confound results, but this limitation is quickly being overcome. The approach and results presented here offer promising av- enues for understanding the complex linkages between ocean climate, salmon-borne nutrients, and riparian vegetation and provides tools for the reconstruction of prehistoric salmon abundance. Reconstructions provide otherwise unobtainable knowledge of long-term salmon abundance patterns, which will be essential for making informed conservation and management decisions.

\section{ACKNOWLEDGMENTS}

We thank Paul Sheppard, Clifford Kraft, David Peterson, Ze'ev Gedalof, Robert Francis, Mason Bryant, and an anonymous reviewer for their help and comments. Research support by the National Science Foundation (DEB 98-06575), the Pacific Northwest Research Station of the US Forest Service, and the University of Washington is gratefully acknowledged.

\section{Literature Cited}

Bartz, K. 2002. The effects of salmon-derived nutrients on riparian forest structure and composition in southwest Alaska. Thesis. University of Washington, Seattle, Washington, USA.

Ben-David, M., M. Flynn, and D. M. Schell. 1997. Annual and seasonal changes in the diet of martens: evidence from stable isotope analysis. Oecologia 111:280-291.

$\rightarrow$ Ben-David, M., T. A. Hanley, and D. M. Schell. 1998. Fertilization of terrestrial vegetation by spawning Pacific salmon: the role of flooding and predator activity. Oikos 83: 47-55.

Bilby, R. E., R. R. French, and P. A. Bisson. 1996. Incorporation of nitrogen and carbon from spawning coho salmon into the trophic system of small streams: evidence from stable isotopes. Canadian Journal of Fisheries and Aquatic Science 53:164-173.

Bilby, R. E., R. R. French, P. A. Bisson, and J. K. Walter. 1998. Response of juvenile coho salmon (Oncorhynchus kisutch) and steelhead (O. mykiss) to the addition of salmon carcasses to two streams in southwestern Washington, USA. Canadian Journal of Fisheries and Aquatic Science 55:1908-1918.

$\rightarrow$ Biondi, F., A. Gershunov, and D. R. Cayan. 2001. North Pacific decadal climate variability since 1661 . Journal of Climate 14:5-10.

$\rightarrow$ Cederholm, C. J., M. D. Kunze, T. Murota, and A. Sibatani. 1999. Pacific salmon carcasses: essential contributions of nutrients and energy for aquatic and terrestrial ecosystems. Fisheries 24:6-15.

Chabot, B. F., and H. A. Mooney, editors. 1985. Physiological ecology of North American plant communities. Chapman and Hall, New York, New York, USA.

Cook, E. R. 1985. A time series approach to tree-ring standardization. Dissertation. University of Arizona, Tucson, Arizona, USA.

Finney, B. P., I. Gregory-Eaves, J. Sweetman, M. S. V. Douglas, and J. P. Smol. 2000. Impacts of climatic change and fishing on Pacific salmon abundance over the past 300 years. Science 290:795-799.

$\rightarrow$ Francis, R. C., and S. R. Hare. 1994. Decadal-scale regime shifts in the large marine ecosystems of the Northeast Pacific: a case for historical science. Fisheries Oceanography 3:279-291.

Garfinkel, H. L., and L. B. Brubaker. 1980. Modern climatetree growth relationships and climatic reconstruction in sub-arctic Alaska. Nature 286:872-874.

$\rightarrow$ Hare, S. R., N. J. Mantua, and R. C. Francis. 1999. Inverse production regimes: Alaska and West Coast Pacific salmon. Fisheries 24:6-14.

Harris, A. S., and W. A. Farr. 1974. The forest ecosystem of 
southeast Alaska 7: forest ecology and timber management. USDA Forest Service General Technical Report PNW-25.

Helfield, J. M. 2001. Interactions of salmon, bear, and riparian vegetation in Alaska. Dissertation. University of Washington, Seattle, Washington, USA.

Helfield, J. M., and R. J. Naiman. 2001. Effects of salmonderived nitrogen on riparian forest growth and implications for stream productivity. Ecology 82:2403-2409.

$\rightarrow$ Hildebrand, G. V., S. D. Farley, C. T. Robbins, T. A. Hanley, K. Titus, and C. Servheen. 1996. Use of stable isotopes to determine diets of living and extinct bears. Canadian Journal of Zoology 74:2080-2088.

$\rightarrow$ Hildebrand, G. V., T. A. Hanley, C. T. Robbins, and C. C. Schwartz. 1999. Role of brown bears (Ursus arctos) in the flow of marine nitrogen into a terrestrial ecosystem. Oecologia 121:546-550.

Holmes, R. 1983. Computer assisted quality control in treering dating and measurement. Tree-Ring Bulletin 44:6975 .

Hyatt, T. L., and R. J. Naiman. 2001. The residence time of large woody debris in the Queets River, Washington, USA Ecological Applications 11:191-202.

$\rightarrow$ Kline, T. C., Jr., J. J. Goering, O. A. Mathisen, P. H. Poe, and P. L. Parker. 1990. Recycling of elements transported upstream by runs of Pacific salmon. Canadian Journal of Fisheries and Aquatic Science 47:136-144.

$\rightarrow$ Mantua, N. J., S. R. Hare, Y. Zhang, J. M. Wallace, and R. C. Francis. 1997. A Pacific interdecadal climate oscillation with impacts on salmon production. Bulletin of the Amer ican Meterological Society 78:1069-1080.

Naiman, R. J., R. E. Bilby, D. E. Schindler, and J. M. Helfield. 2002. Pacific salmon, nutrients and dynamics of freshwater and riparian ecosystems. Ecosystems, in press.
Oliver, C. D., and B. C. Larson. 1996. Forest stand dynamics. John Wiley and Sons, New York, New York, USA.

Phipps, E. L. 1985. Collecting, preparing, crossdating and measuring tree increment cores. Water-Resources Investigations Report number 85-4148. U.S. Geological Survey, Lakewood, Colorado, USA.

Rogers, D. E., and B. J. Rogers. 1998. Spawning ground surveys in the Wood River Lakes. University of Washington Alaska Salmon Program Technical Report Number FRIUW-9803. University of Washington School of Aquatic and Fishery Sciences, Seattle, Washington, USA.

SPSS. 1999. SPSS for Windows, Release 10. 0.5. SPSS, Chicago, Illinois, USA.

Van Cleve, K., and J. Yarie. 1986. Interaction of moisture, temperature and soil chemistry. Pages 160-189 in K. Van Cleve, F. S. Chapin, III, P. W. Flanagan, L. A. Viereck, and C. T. Dyrness, editors. Forest ecosystems in the Alaskan taiga. Springer-Verlag, New York, New York, USA.

Wiles, G., and P. E. Calkin. 1995. Mountain Lake Alaska Sitka spruce tree ring chronology. Submission number 350M 5910-13920. In H. Grissno-Mayer, editor. International tree-ring databank. IGBP PAGES/World Data Center for Paleoclimatology. NOAA/NGDC Paleoclimatology Program, Boulder, Colorado, USA.

Willson, M. F., S. M. Gende, and B. H. Marston. 1998. Fishes and the forest: expanding perspectives on fish-wildlife interactions. BioScience 48:455-462.

Wipfli, M. S., J. Hudson, and J. Caouette. 1998. Influence of salmon carcasses on stream productivity: response of biofilm and benthic macroinvertebrates in southeastern Alaska, USA. Canadian Journal of Fisheries and Aquatic Science 55:1503-1511. 